\title{
Antimicrobial silver nanoparticle induces organ deformities in the developing Zebrafish (Danio rerio) embryos
}

\author{
Rajaretinam Rajesh Kannan ${ }^{1}$, Arockya Jeyabalan Avila Jerley ${ }^{2}$, Muthiah Ranjani', \\ Vincent Samuel Gnana Prakash ${ }^{1}$
}

\footnotetext{
${ }^{1}$ International Centre for Nanobiotechnology (ICN), Centre for Marine Science and Technology Campus, Manonmaniam Sundaranar University, Kanyakumari, India.

${ }^{2}$ Department of Microbiology, N.M.S.S. Vellaichamy Nadar College, Madurai, India.

First two authors are equally contributed.

Email: vsgprakash.icn@gmail.com
}

Received 12 February 2011; revised 26 February 2011; accepted 3 March 2011.

\begin{abstract}
Silver Nanoparticles were synthesized by Escherichia coli using Silver nitrate in the growth medium and characterized in X-Ray Diffraction, UVVis Spectrophotometer and Scanning Electron Microscope. They exhibited antimicrobial activity against human pathogens except Escherichia Coli. Nanoparticles were impregnated in yarn and analyzed for their inhibition in the broth culture. The Minimal Inhibitory Concentratio was calculated for the human pathogens in Microtitre plate. The toxicity assessment of the nanoparticles in the embryonic Zebrafish showed many organogensis deformities like cardiac malformations, eye and head edema, tail and trunk flexure were observed in the organ system of the developing embryos for 1 to 5 day post fertilization in different concentrations of $\mathbf{A g}$ Nanoparticles. The Organogenesis disruptive effects were found in $14-20 \mathrm{ng} / \mathrm{ml}$ of silver nanoparticles but the inhibition was found in $4-10 \mathrm{ng} / \mathrm{ml}$ for the pathogens in vitro and $10 \mathrm{ng} / \mathrm{ml}$ in embryos. Nevertheless, in Cardiac assay, the Heart Beat rates were calculated as 42 - 45 for 15 Sec in the concentrations ranging from $10-20 \mathrm{ng} / \mathrm{ml}$ of Silver nanoparticles. The blood flows, rhythmicity, contractility of heart beat rates were observed normal. The Mean value of blood Cell counting did not showed any notable effects in the Nanoparticle treated Zebrafish embryos and control. The LC50 value for the Biosynthesized nanoparticle was at $22 \mathrm{ng} / \mathrm{ml}$ in all the developmental stages of the embryos. Our results shows silver nanoparticles disrupts the normal organogenesis during development and further detailed studies are needed to prove silver nanopartcles are an antimicrobial agent for use in humans.
\end{abstract}

Keywords: Biocidal Effect; X-ray Diffraction; Scanning Electron Microscope; Organogenesis; Deformities; Cardiac Assay

\section{INTRODUCTION}

Microorganisms such as bacteria, yeast and fungi play an important role in remediation of toxic metals through reduction of metal ions; this is considered interesting as nanofactories [1]. Nanoparticles has a significant potential for a wide range of biological applications such as antifungal agents, antibacterial agents for antibiotic resistant bacteria, preventing infections, healing wounds and anti-inflammatory [2]. The new technology of impregnation of silver nanoparticles are now commercially available and silver coated dressings are used extensively for wound management, particularly in burn wounds $[3,4]$, Chronic leg ulcers [5], diabetic wounds [6] and traumatic injuries. The dressing component are also varies, as nylon, mesh, and hydrocolloid or methyl cellulose. The interactions of silver nanoparticles with biosystems are just beginning to be understood, and these particles are increasingly being used as microbicidal agents. A new generation of dressing with antimicrobial agents like silver and biopolymer was developed to reduce or prevent infections.

Zebrafishes have unique applications over other vertebrate model system (mouse, rat) [7]. The metabolism, physiology and development of Zebrafish are comparable to humans and therefore Zebrafish is highly relevant model for toxicity, safety and efficacy testing. Genetic screens of Zebrafish phenotypes show similarities in human diseases and protein sequences of drug binding proteins [8]. Zebrafish have served as a vital model system for screening drug targets for curing human diseases. Large numbers of embryos can be generated rapidly at low cost, which can serve as an ideal in vivo assay for 
screening biocompatibility, pharmacological efficacy, and toxicity of nanoparticle. This study was aimed at synthesis of microbial Silver nanoparticles and assay its antimicrobial properties and evaluating its human compatibility.

\section{MATERIALS AND METHODS}

\subsection{Biosynthesis and Characterization of $\mathrm{Ag}$ Nanoparticles}

The silver seeds were prepared by rapidly injecting 0.5 $\mathrm{ml}$ of $10 \mathrm{mM} \mathrm{NaBH}_{4}$ into an aqueous solution containing $0.5 \mathrm{ml}$ of $0.01 \mathrm{M} \mathrm{AgNO}_{3}$ and $20 \mathrm{ml}$ of $0.001 \mathrm{M}$ Sodium citrate. It was stirred for $5 \mathrm{~min}$ and incubated for 90 minutes at $37^{\circ} \mathrm{C}$. The spherical silver hydrosols were prepared by adding $3 \mathrm{ml}$ of the silver seed solution to the aqueous solution of sodium citrate and silver nitrate solution $(100 \mathrm{ml}, 0.001 \mathrm{M})$. This solution was inoculated with $10 \mathrm{ml}$ of $E$. coli culture broth and incubated at $37^{\circ} \mathrm{C}$ for $24 \mathrm{hrs}$ until the color changes to greenish yellow. The solution was filtered in $0.22 \mu \mathrm{m}$ filter to remove the microbes and the nanoparticles were washed with nanopure water using centrifugation to remove the chemicals involved in nanoparticle synthesis. The synthesized silver nanoparticles were characterized by UV-Vis Spectroscopy, X-Ray Diffraction and Scanning Electron Microscope for estimation of crystalline structure, mean size and morphology. The nanoparticle pellets were resuspended in nanopure water for assaying Antimicrobial properties and the physiological studies in Zebrafish embryos.

\subsection{Antimicrobial Activity and Minimal Inhibitory Concentration}

The nutrient broth was prepared, sterilized and inoculated with fresh culture of human pathogens (Figure 1) and incubated at $37^{\circ} \mathrm{C}$ for 24 hours. After incubation the cultures were centrifuged at $12000 \mathrm{rpm}$ and the supernatant was used for further experiments. Nutrient broth plates were supplemented with 1 - $15 \mathrm{ng} / \mathrm{ml}$ concentration of Silver nano particles and tested with pathogens for its antimicrobial property. Antimicrobial activity was determined by the microtiter broth dilution method [9]. Dilutions of the Silver nanoparticles (1 - $15 \mathrm{ng} / \mathrm{ml})$ were added in 1\% DMSO to each well of the 96 well microtiter plates containing fixed volume of Nutrient broth. Each well was inoculated with bacteria $\left(10^{5} \mathrm{CFU} \mathrm{m}{ }^{-1}\right)$ and incubated at $37^{\circ} \mathrm{C}$ for $24 \mathrm{~h}$. The MIC was calculated at which no growth of bacteria was observed for all the microbial pathogens shown in Figure 1.

\subsection{Preparation of Silver Impregnated Dressings and Antimicrobial Analysis}

$10 \mathrm{~g}$ of white degreased yarn was cut into many pieces of

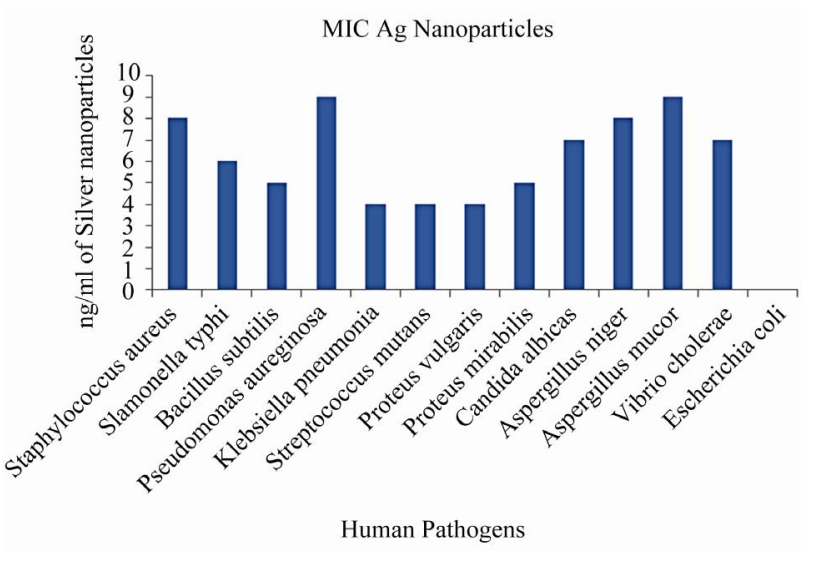

Figure 1. Minimal Inhibitory Concentrations (MIC) of Ag Nanoparticles in the Human pathogens.

$1 \mathrm{~cm}^{2}$ each. This was immersed in the $10 \mathrm{ng} / \mathrm{ml} \mathrm{Ag}$ Nanoparticles solution and it was squeezed and dried in hot air oven. The yarn was further washed twice with Nanopure water. The Ag coated dressing was placed in to the sterile vial containing $80 \mu \mathrm{l}$ of Nanopure water for 10 minutes and $2.2 \mathrm{ml}$ of nutrient broth was added to each vial to make the volume up to $3 \mathrm{ml} .10 \mu \mathrm{l}$ of bacterial suspension of the selected pathogens were inoculated into the test tubes containing antimicrobial silver dressing. These test tubes were incubated at $35^{\circ} \mathrm{C}$ for 24 hours. After incubation the bacteria suspensions were spread on the blood agar and nutrient agar plates, incubated overnight at $37^{\circ} \mathrm{C}$ and the growth of the organisms were observed.

\subsection{Breeding and Maintenance of Zebrafish Embryos}

Zebrafishes were bred and maintained in Fish Culture facility of International Centre for Nanobiotechnology, CMST, M. S. University. Zebrafishes were maintained in $30 \mathrm{~L}$ tanks at $28^{\circ} \mathrm{C}$ with $14 \mathrm{~h}: 10 \mathrm{~h}$ light/dark cycle. Following successful breeding eggs fell through the mesh, and was subsequently collected from the bottom of tanks. Zebrafishes were maintained according to Westerfield, 1989 [10]. Zebrafish embryos were raised in E3 medium (5 mM NaCl, $0.17 \mathrm{mM} \mathrm{KCl}, 0.4 \mathrm{mM} \mathrm{CaCl}_{2}$ and 0.16 $\mathrm{mM} \mathrm{MgSO}_{4}$ ). For Zebrafish embryo chemical experiments 1\% DMSO was used as a vehicle for small molecules to permeate the embryo. Eggs containing dead or obviously poor quality embryos were removed. The remaining embryos were used for Organogenesis and Physiological effects [11].

\subsection{Effect of Ag Nanoparticles in the Organogenesis of Zebrafish Embryonic Development}

$10 \mu \mathrm{l}$ of the human pathogens and $1-25 \mathrm{ng} / \mathrm{ml}$ of $\mathrm{Ag}$ 
Nanoparticles were treated in the $1-5 \mathrm{dpf}$ (days post fertilization) Zebrafish embryos in the 48 well microtitre plates to observe the Organogenesis and Physiological effects. A parallel control was made in all the in vivo studies. The Biocompatibility and the physiological effects of the silver Nanoparticles were monitored in the developing embryos. The Heart beat rates and the blood flow levels were analyzed in the Image and the Video. The highest non lethal concentration was also reported. The RBC and WBC counting of the adult Zebrafish embryos were carried out by cutting the tail of the embryos by sharp blade under Microscope (Motic) and $0.5-1 \mu \mathrm{l}$ of blood was pipetted out in $0.5-10 \mu \mathrm{l}$ Eppendorf Micropipette and diluted in RBC and WBC dilution fluid and counted in Hemocytometer.

\section{RESULTS}

\subsection{Synthesis and Characterization of Ag Nanoparticles}

All diffraction peaks correspond to the characteristic face centered cubic (FCC) silver lines. The analysis was carried out in $2 \theta$ range $20^{\circ}-80^{\circ}$, with step size $0.05^{\circ}$ in a Rigaku D-Max B diffractometer. These diffraction lines observed at $2 \theta$ angle $38.1^{\circ}, 44.3^{\circ}, 64.4^{\circ}$, and $77.5^{\circ}$ respectively, have been indexed as (111), (200), (220) and (311) respectively. X-Ray Diffraction patterns were analyzed to determine peak intensity, position and width. Full width at half-maximum (FWHM) data was used with the scherrer's formula to determine mean particle size. Scherrer's equation is given by

$$
d=\frac{0.9 \lambda}{\beta \operatorname{con} \theta}
$$

Where ' $d$ ' is the mean diameter of the nanoparticles ' $\lambda$ ' is wavelength of X-ray radiation source, $\theta$ is the angular FWHM of the XRD peak at the diffraction angle $\theta$. The mean size of nanoparticles estimated by XRD was $13 \mathrm{~nm}$ and shown in Figure 2. The SEM micrograph of

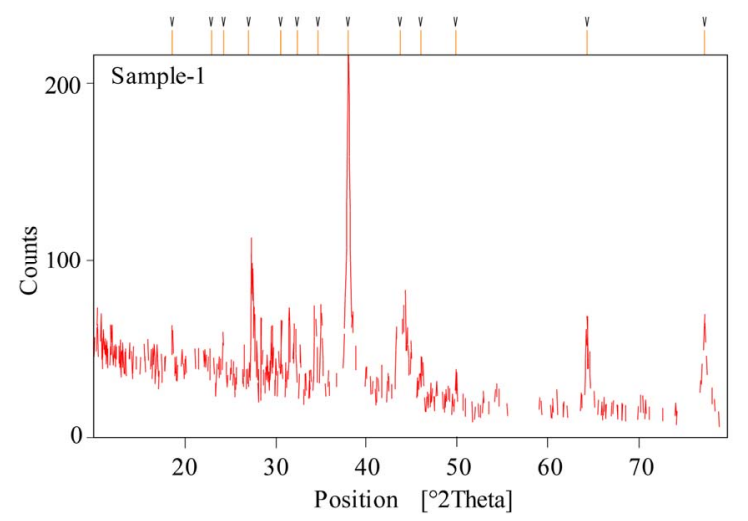

Figure 2. XRD analysis of Ag nanoparticles produced by $E$. coli. bacterial cell biomass treated with silver nanoparticles in which silver has been found adhered to the bacterial cell wall surface and shown in Figure 3. The UV-Vis Spectrophotometer of $\mathrm{Ag}$ nanoparticles showed the value of $430 \mathrm{~nm}$.

\subsection{In vitro Antimicrobial Assay of Ag Nanopar- ticle}

Minimum Inhibitory Concentration of the Silver nanoparticles for the human pathogens was ranging from 4 $10 \mathrm{ng} / \mathrm{ml}$ and is shown in Figure 1 and in the spread plate method. The silver nanoparticle impregnated yarn and control yarn is shown in Figures 4(a) and 4(b). The bactericidal effect of the silver impregnated yarn showed no microbial growth was observed in the microbial plate culture and is shown in Figure 5 and Figure 6. Thus all silver-impregnated dressings investigated for antagonistic property, on all the human pathogen at the concentration of $10 \mathrm{ng} / \mathrm{ml}$ had inhibiting property. Interestingly, the synthesized nanoparticle did not inhibit the growth of E. coli.

\subsection{Physiological and Organogenesis Effect of Silver Nanoparticles}

\subsubsection{Organogenesis Effect}

To determine the effect of different doses of Ag nanopar-

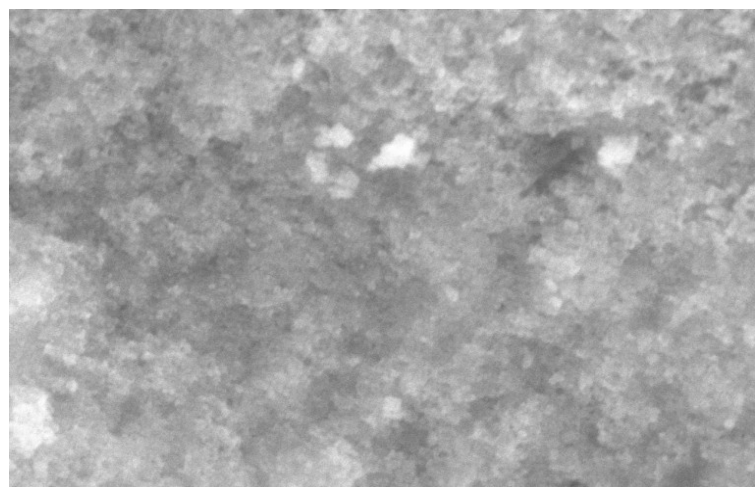

Figure 3. SEM analysis-Ag nanoparticles.

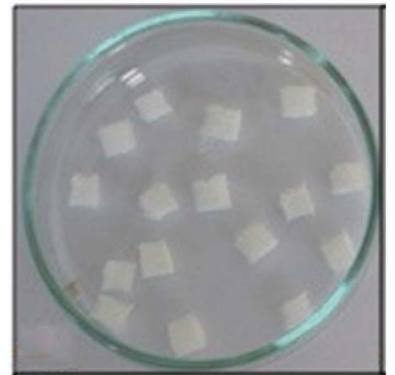

(a)

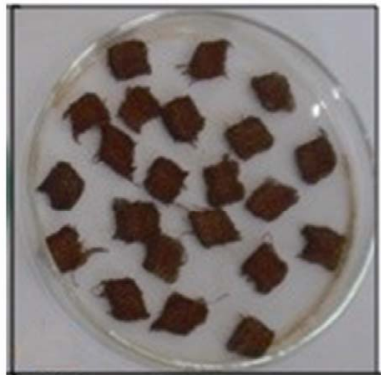

(b)
Figure 4. (a) Control yarn, (b) Ag nanoparticles impregnated yarn. 


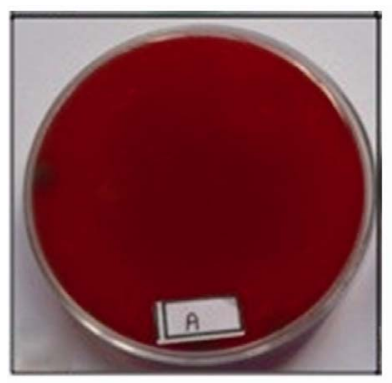

(a)

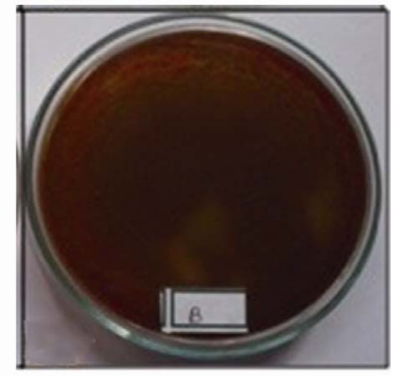

(b)
Figure 5. (a) and (b) Showing the antimicrobial properties of Ag nanopartcles for Streptococcus mutans.

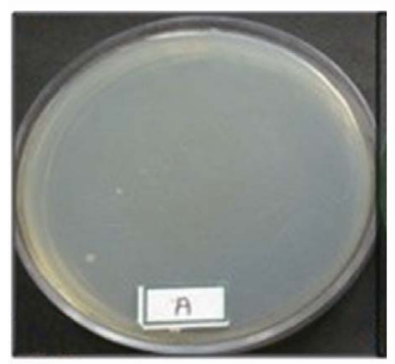

(a)

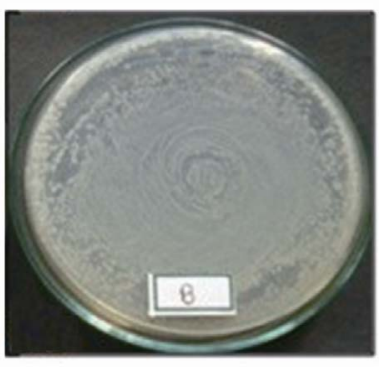

(b)
Figure 6. (a) and (b) Showing the antimicrobial properties of Ag nanoparticles for Bacillus Subtilis ((a) No growth observed in Ag impregnated yarn, (b) Growth observed in the control yarn).

ticles on embryonic development, we treated Ag nanoparticles in stages $1 \mathrm{dpf}$ to $5 \mathrm{dpf}$ Zebrafish embryos and carefully monitored the Organogenesis in the embryos $(24,48,72,96$, and $120 \mathrm{hpf})$, the results are shown in Figures 7(a)-7(j). Different organogenesis effects were observed in the developing embryos. The different phenotypic deformities were observed in the concentration of the $14-20 \mathrm{ng} / \mathrm{ml}$ of Ag Nanoparticles treated embryos. Many physiological changes were observed in the embryos from $24 \mathrm{hpf}$ to $120 \mathrm{hpf}$ Figures 7(a)-7(j). The organogenesis effect like finfold abnormalities, tail flexure and spinal truncation, cardiac malformation, yolk sac edema, head edema, eye deformity, blood accumulation and tumor formations in zebrafish embryos were observed from 1 - 5 dpf embryos treated Ag nanoparticles. Multiple organogenesis deformities were observed in the $16-18 \mathrm{ng} / \mathrm{ml}$ and the LC50 value of the embryos were observed at $20 \mathrm{ng} / \mathrm{ml}$ to $22 \mathrm{ng} / \mathrm{ml}$ of $\mathrm{Ag}$ Nanoparticles. They lead to the death of the embryos in all the 5 stages ( $1 \mathrm{dpf}$ to $5 \mathrm{dpf}$ ) after 36 - $50 \mathrm{hrs}$ of the treatment. $96 \mathrm{Mi}-$ crotitre plates with embryos were inoculated with $5 \mu \mathrm{l}$ of pathogens and $10 \mathrm{ng} / \mathrm{ml}$ of silver Nanoparticles were added in the Embryo Rearing Solutions and the inhibition concentration at in vivo studies are similar to the inhibition concentration of in vitro studies.

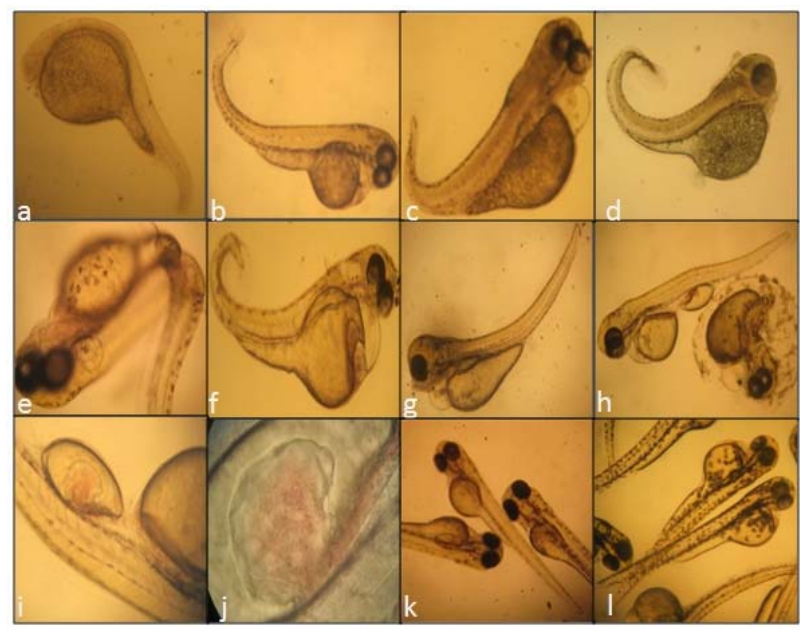

Figure 7. Organogenesis effects of Ag Nanoaparticles from 1 dpf to $5 \mathrm{dpf}$ of Zebrafish embryos ((a) to (i) - 10x, (j)-40x and (k) and (1)-10x) (a) $1 \mathrm{dpf}$ showing eye deformity at 15 $\mathrm{ng} / \mathrm{ml}$; (b) $2 \mathrm{dpf}$ showing trunk and spinal cord flexure $16 \mathrm{ng} / \mathrm{ml}$; (c) 2 dpf showing tail flexure and yolk edema $14 \mathrm{ng} / \mathrm{ml}$; (d) 3 dpf showing cardiac malformation and yolk edema $15 \mathrm{ng} / \mathrm{ml}$; (e) 3 dpf showing trunk braekage at $23 \mathrm{ng} / \mathrm{ml}, 16 \mathrm{ng} / \mathrm{ml}$; (f) 3 dpf showing tail flexure and necrosis effect in the yolk region $15 \mathrm{ng} / \mathrm{ml}$; (g) 4 dpf showing pericardial bulging, cardiac malformation and head edema $16 \mathrm{ng} / \mathrm{ml}$; (h) $5 \mathrm{dpf}$ howing blood accumulation and damage in the blood vessels at $20 \mathrm{ng} / \mathrm{ml}$; (i) $5 \mathrm{dpf}$ abnormality in the cardiac and yolk edema leads to death $20 \mathrm{ng} / \mathrm{ml}$; (j) $5 \mathrm{dpf}$ tumour formation and blood accumulationin the $20 \mathrm{ng} / \mathrm{ml}$ of the nanoparticles; (k) $3 \mathrm{dpf}$ control embryos; (1) 5 dpf control embryos.

\subsubsection{Cardiac Assay and Blood Cell Counting}

The cardiac malformations did not affect the Heart Beat Rates (HBR) and the normal heart beat ranges from 42 43 and similar mean value of heart beat rate of 43 for 15 seconds was recorded. The heart beat rates were normal and in the malformed heart of the nanoparticle treated embryos. The rhythmicity and blood flow level were monitored in the simple microscope and the effects were observed in 15 - $17 \mathrm{ng} / \mathrm{ml}$ of the Ag Nanoparticles. The blood flow level, contractility and rhythmicity were normal in all the abnormal embryos like Yolk sac edema, tail and spinal cord flexure, finfold abnormality, cardiac malformation and head edema. These findings suggest that phenotypic deformities of Ag Nanoparticles did not affect the Hematopoiesis process and vasculogenesis at the concentration of $14-20 \mathrm{ng} / \mathrm{ml}$, but the vasculogenesis and rhythmicity of blood flow were affected above the concentration of $20 \mu \mathrm{g} / \mathrm{ml}$, tumor formation and blood accumulation were observed and shown in Figure 7(j). The Blood cell counting was carried out in the Hemocytometer in all the defected embryos from $3 \mathrm{dpf}$ $5 \mathrm{dpf}$ and the mean results were tabulated in Figures 8(a) and $\mathbf{8}(\mathbf{b})$. The mean value of $\mathrm{WBC}$ and $\mathrm{RBC}$ counts were seemed to be normal and showed very minor dif- 
ferences in the blood cell count in $10-16 \mathrm{ng} / \mathrm{ml}$ concentration in the Zebrafish embryos.

\section{DISCUSSION}

Nanotechnology involves the tailoring of materials at atomic level to attain unique properties, which can be suitably manipulated for the desired applications [12]. The new age drugs are nanoparticle which can fight human pathogens [13]. In recent years, extensive studies have been undertaken on the use of antimicrobial properties of silver, incorporated within medical devices. The aim of this study was to prepare a formulation containing silver ion, which could be applied for wound dressing. In Nanoparticle preparation appearance of light brown color in solution indicates the formation of silver nanoparticles [14]. Thus, it was evident that the metabolites excreted by the culture exposed to silver could reduce silver ions, clearly indicating that the reduction of the ions occur extracellularly through reducing agents released into the solution by $E$. coli. The silver nanoparticles were characterized by UV-Visible spectroscopy and this technique has proved to be a very useful tech-

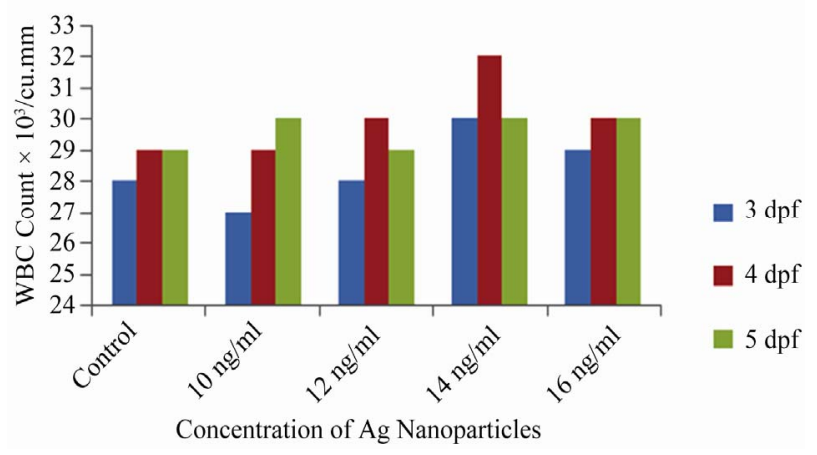

(a)

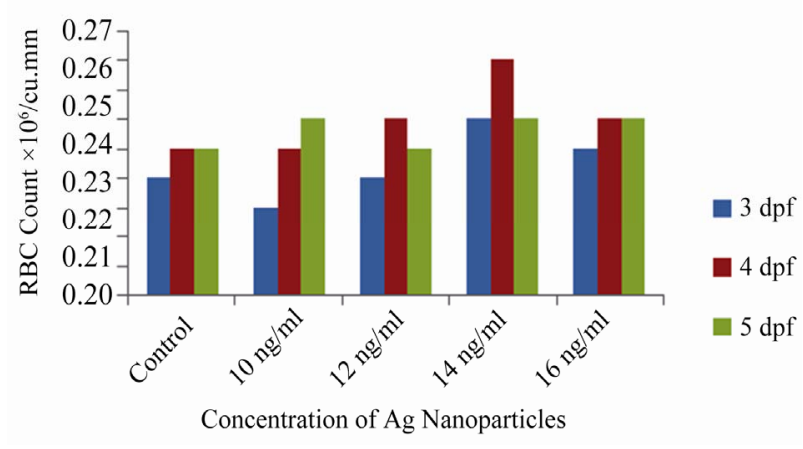

(b)

Figure 8. (a) Level of WBC Count in different concentration of Ag Nanoaparticles in 3 - 5 dpf embryos. (WBC Count $\times$ $10^{3}$ /cu.mm), (b) Level of RBC Count in different concentration of Ag Nanoaparticles in $3-5 \mathrm{dpf}$ embryos. (RBC Count $x$ 106 cu.mm). nique for the analysis of nanoparticles. This event clearly indicated that the reduction of the ions occured extracellularly through reducing agents released into the solution by $E$. coli, as it showed a strong and broad, surface peak at $430 \mathrm{~nm}$. The solution was extremely stable with no evidence of flocculation of the particles even several weeks after reaction. This showed that the silver cations were highly reactive and tend to bind strongly to electron donor groups containing sulfur, oxygen or nitrogen [15] and this indicated that E. coli can synthesize silver nanoparticles extracellularly (Figure 3 ).

Silver nanoparticles are the important product in the nanotechnology industries for many clinical applications, but the risk factors of toxicity was least studied [16]. In this work we have analyzed the organogenesis effect of antimicrobial Ag Nanoparticles. Nanoparticles of silver have been studied as coating materials [17]. Hence in this present work a silver nanoparticle were impregnated in the dressing yarn and was found to have antimicrobial effects, proved the inhibition of human pathogens as shown in Figure 1. This approach was a simple method for the synthesis and coating of silver nano particles in the yarn, so that the yarn would inhibit the microbial growth in the wound. It was found that the nanoparticles were very novel for its antimicrobial activity against the human pathogens. The bactericidal property of these nanoparticles depends on their stability in the growth medium, since this imparted greater retention time for bacterium-nanoparticle interaction and the stability was confirmed by UV-Vis Spectrophotometer. The purified Ag nanoparticles had no effect against $E$. coli. There was no reduction in the growth at Microtitre plate. This opens up a field of interesting, as how E. coli resisted the Ag Nanoparticles. These were correlated to the result, in which the process of synthesis of Ag Nanoparticles did not inhibit the growth of E. coli in the broth. Zebrafish is an ideal organism to study the organogenesis effect. Hence, to determine the effect of dose dependent and organogenesis we have analyzed the physiological effects in the embryos for the Ag Nanoparticles and similar dose dependant studies in Zebrafish embryos were also carried out for Ag Nanoparticles, but it showed toxic effects in lesser concentration [18]. In the present study, the toxicity was observed from $14 \mathrm{ng} / \mathrm{ml}$ of the silver nano particles but $10 \mathrm{ng} / \mathrm{ml}$ of the $\mathrm{Ag}$ nanoparticles inhibited the bacterial growth in vitro and in vivo in the Zebrafish embryonic model. The results of the deformities were shown in Figures 7(a)-7(j) and similar deformities were also observed in the embryonic development of Zebrafish [18]. The Nano-ZnO toxicity and deformities were also studied in the Zebrafish [19].The control embryos which showed the pigmentation that the Ag Nanoparticles treated embryos, hence it was confirmed that the Ag nanoparticles were influencing the 
pigment formations. The cardiac malformations and yolk edema observed in this study is similar to the zebrafish treated DCA and cadmium $[20,21]$. The lethality and the phenotypic deformalities of the $\mathrm{Ag}$ Nanoparticles are higher in the Zebrafish embryos were reported in the earlier studies [18]. The shrunken ventricular myocardium observed in cardiac malformed zebrafish induced by nanoparticles were similar to the observation in zebrafish treated with Ag Nanopartcles and TCDD [18,22]. Thus it was proving that the toxic effects of the $\mathrm{Ag}$ nanoparticles are similar to TCDD and chemically synthesized nanoparticle [18]. The preclinical studies of the silver nanoparticles and the physiological effects were analysed in the Zebrafish embryos and it was proving that if the Ag nanoparticles yarn formulation would be applied to the pregnant women that might affect fetus Organogenesis. However thorough studies have to be mde in higher vertebrates to prove organ deformities. This study proves the Biological synthesis and Chemical synthesis [18] of silver nanoparticles are toxic to the developing embryos by this embryonic model study in Zebrafish. The blood cell counting (WBC \& RBC) of the Zebrafish did not show notable effects in blood cell formations and the blood vessels. The blood cell count was normal in both the Ag nanoparticles treated embryos and in the control. In the cardiac assay the Heart beat rates and the rhythmicity (atrial and ventricular) were observed in the microscope, only the pericardial edema and the malformation was observed in the heart, but the Heart Beat Rates were normal in both the control and the treated embryos. It proved that the Ag nanoparticle affected the organogenesis process of cardiac muscle formation without affecting the Heart Beat Rates, and proving that the transcriptional regulatory mechanism for the myocardiac muscle formation was affected and this will be studied by functional genomic approach. This is the first report on the Ag Nanoparticles which did not affect the Hematopoietic process and Heart Baet Rates, earlier there was no in vivo studies in Zebrafish models. In the similar ay the antimicrobial properties of the anti MRSA molecule and the compound toxicity for cardiac assay and pathogenic infection study was analyzed in the Zebrafish embryos [11]. Also Silver-coated nanoparticles were the most effective among all the nanoparticles without significant cytotoxicity, suggesting their use as antimicrobial additives in the process of fabrication of ambulatory and nonambulatory medical devices [23]. In this work the Minimum Inhibitory concentration $(4-10 \mathrm{ng} / \mathrm{ml})$ of $\mathrm{Ag}$ nanoparticle for microorganisms are non toxic to the physiology and organogenesis of the Zebrafish embryos, but the Inhibitory Concentration level of the $\mathrm{Ag}$ Nanoparticles and the nanotoxic level was assessed in vivo in the fish model. The lethal and non lethal concentration was reported in the in vivo studies, confirmed that the silver nanoparticles did not affect the heart beat rates and Hematopoiesis process. The stability of the nanoparticles were checked in the Embryo Rearing Solution (ERS) by UV-Vis spectroscopy showing the same wavelength $(420 \mathrm{~nm}$ and 430 $\mathrm{nm})$. The Biosynthesized silver nanoparticles does not showed any notable different toxic effect in the Zebrafish embryonic model at the Minimum Inhibitory Concentration of microbes but if it exceeds the level, Ag Nanoparticle will be more toxic to the developing embryos and shown in Figure 7. Further studies on higher vertebrate models (mouse, dog, monkey, etc.) are needed for the dose of silver nanoparticle which does not cause organ deformities in embryos.

\section{REFERENCES}

[1] Fortin, D. and Beveridge, T.J. (2000) Mechanistic routes towards biomineral surface development. In: E. Bacuerlein, Ed., Biomineralisation: From Biology to Biotechnology and Medical Application, Wiley-VCH, Verlag, 294.

[2] Taylor, P.L., Ussher, A.L. and Burrell, R.E. (2005) Impact of heat on nanocrystalline silver dressings. Part I: Chemical and biological properties. Biomaterial, 26, 7221-7229.

[3] Ross, D.A., Phipps, A.J. and Clarke, J.A. (1993) The use of cerium nitrate-silver sulphadiazine as a topical burns dressing. British Journal of Plastic Surgery, 46, 582-584. doi:10.1016/0007-1226(93)90110-W

[4] Caruso, D.M., Foster, K.N., Hermans, M.H. and Rick, C. (2004) Aquacel Ag in the management of partial-thickness burns: Results of a clinical trial. Journal of Burn Care \& Research, 25, 89-97. doi:10.1097/01.BCR.0000107202.85453.63

[5] Karlsmark, T., Agerslev, R.H., Bendz, S.H., Larsen, J.R., Roed-Petersen, J. and Andersen, K.E. (2003) Clinical performance of a new silver dressing, contreet foam, for chronic exuding venous leg ulcers. Journal of Wound Care, 12, 351-354

[6] Hilton. J.R., Williams, D.T., Beuker, B., Miller, D.R. and Harding, K.G. (2004) Wound dressings in diabetic foot disease. Clinical Infectious Diseases, 39, (Suppl. 2) S100-S103. doi: 10.1086/383270

[7] Zon, L.I. and Peterson, R.T. (2005) In Vivo Drug Discovery in the Zebrafish. Nature Reviews Drug Discovery, 4, 35-44. doi:10.1038/nrd1606

[8] Den Hertog, J. (2005) Chemical genetics: Drug screens in Zebrafish. Bioscience Reports, 25, 289-297. doi:10.1007/s10540-005-2891-8

[9] Kim, S. and Oh, K.B. (2002) Evaluation of antimicrobial activity of farnesoic acid derivatives. Journal of Microbiology and Biotechnology, 12, 1006-1009.

[10] Westerfield, M. (1989) The Zebrafish book: A guide for the laboratory use of Zebrafish (Danio Rerio), University of Oregon Press, Eugene.

[11] Rajaretinam, R.K. and Vincent, S.G.P. (2010) Isolation of a novel bioactive compound from Rhizophora mucronata for Methicillin resistant Staphylococcus aureus (MRSA) 
and compound toxicity assessment in Zebra fish embryos Journal of Pharmacy Research, 3, 2000-2003.

[12] Gleiter, H. (2000) Nanostructured materials, basic concepts and microstructure. Acta Materialia, 48, 1-12. doi:10.1016/S1359-6454(99)00285-2

[13] Baker, C., Pradhan, A., Pakstis, L., Pochan, D.J. and Shah, S.I. (2005) Synthesis and antibacterial properties of silver nanoparticles. Journal of Nanoscience and $\mathrm{Na}$ notechnology, 5, 244-249.

[14] Sastry, M., Patil, V. and Sainkar, S.R. (1998) Electrostatically controlled diffusion of carboxylic acid derivatized silver colloidal particles in thermally evaporated fatty amine films. The Journal of Physical Chemistry B, 102, 1404-1410. doi:10.1021/jp9719873

[15] Kowshik, M., Ashtaputre, S., Kharrazi, S., Vogel, W., Urban, J., Kulkarni, S.K. and Paknikar, K.M. (2003) Extracellular synthesis of silver nanoparticles by a silvertolerant yeast strain MKY3. Nanotechnology, 14, 95-101. doi:10.1088/0957-4484/14/1/321

[16] Lee, H.Y., Choi, U.J., Jung, E.J., Yin, H.Q., Kwon, J.T., Kim, J.E., Im, H.T., Cho, M.H., Kim, J.H., Kim, H.Y., Lee, B.H. (2010) Genomics-based screening of differentially expressed genes in the brains of mice exposed to silver nanoparticles via inhalation. Journal of Nanoparticle Research, 12, 1567-1578.

[17] Li, Y., Leung, P., Yao, L., Song, Q.W. and Newton, E. (2006) Antimicrobial effect of surgical masks coated with nanoparticles. Journal of Hospital Infection, 62, 58-63. doi:10.1016/j.jhin.2005.04.015

[18] Lee, K.J., Nallathamby, P.D., Browning, L.M., Osgood,
C.J. and Xu, X.N. (2007) In vivo imaging of transport and biocompatibility of single silver nanoparticles in early development of Zebrafish embryos. ACS Nano, 1, 133-143. doi:10.1021/nn700048y

[19] Bai, W., Zhang, Z., Tian, W., He, X., Ma, Y., Zhao, Y. and Chai, Z. (2010) Toxicity of zinc oxide nanoparticles to zebrafish embryo: A physicochemical study of toxicity mechanism. Journal of Nanoparticle Research, 12, 16451654. doi:10.1007/s11051-009-9740-9

[20] Hallare, A.V., Schirlinga, M., Luckenbacha, T., Kohler, H.R. and Triebskorn, R. (2005) Combined effects of temperature and cadmium on developmental parameters and biomarker responses in Zebrafish (Danio Rerio) embryos. Journal of Thermal Biology, 30, 7-17. doi:10.1016/j.jtherbio.2004.06.002

[21] Williams, F.E., Sickelbaugh, T.J. and Hassoun, E. (2006) Modulation by ellagic acid of DCA-induced developmental toxicity in the Zebrafish (Danio Rerio). Journal of Biochemical and Molecular Toxicology, 20, 183-190. doi:10.1002/jbt.20135

[22] Antkiewicz, D.S., Burns, C.G., Carney, S.A., Peterson, E. and Heideman, W. (2005) Heart malformation is an early response to TCDD in embryonic Zebrafish. Toxicological Sciences, 84, 368-377. doi:10.1093/toxsci/kfi073

[23] Gutierrez, F.M., Olive, P.L., Banuelos, A., Orrantia, E., Nino, N., Sanchez, E.M., Ruiz, F., Bach, H. and Gay, Y.A. (2010) Synthesis, characterization, and evaluation of antimicrobial and cytotoxic effect of silver and titanium nanoparticles. Nanomedicine, 6, 681-688. doi:10.1016/j.nano.2010.02.001 